\title{
Release of Ferulic Acid from Wheat Bran by an Inducible Feruloyl Esterase from an Intestinal Bacterium Lactobacillus acidophilus
}

\author{
Xiaokun WAnG*, Xin Geng, Yukari Egashira and Hiroo SAnAdA \\ Laboratory of Food and Nutrition, Graduate School of Science and Technology, Chiba University, 648 Matsudo, Matsudo, Chiba 271- \\ 8510, Japan
}

Received November 18, 2004; Accepted June 7, 2005

In the present study, the production of a novel feruloyl esterase (FAE) from a typical human intestinal bacterium Lactobacillus acidophilus using various carbon sources was investigated. The results showed that FAE activity was strongly induced by hemicellulosic substances, with the highest activity detected when de-starched wheat bran (DSWB) was used as a carbon source. Moreover, the production was stimulated by the monosaccharides xylose and arabinose, suggesting its particular secretion mechanism. With increasing levels of free ferulic acid (FA) added, the production of FAE increased, reached a peak and declined. Further, on addition of either xylanase or $\alpha$-L-arabinofuranosidase, the amount of FA released from DSWB by the purified FAE from $L$. acidophilus increased from 0 to $12.4 \mathrm{nmol}$ and $3.64 \mathrm{nmol}$, respectively. When the three enzymes existed together, $15.7 \mathrm{nmol}$ of FA was detected. These results indicated that xylanase is predominant and arabinofuranosidase subordinate in their synergistic effect on FA release by FAE.

Keywords: Dietary ferulic acid, Feruloyl esterase, Xylanase, Arabinofuranosidase, Lactobacillus acidophilus

\section{Introduction}

Recently, a great deal of research effort has been focused on dietary ferulic acid (FA) due to its potential health benefits. Many in vitro and in vivo studies have indicated that FA prevents oxidation of low-density lipoprotein (Kikuzaki et al., 2002; Meyer et al., 1998; Nicolosi et al., 1991; Ohta et al., 1997), exhibits inhibitory effects on tumor promotion (Anasoma et al., 1994; Huang et al., 1988) and protects against certain chronic diseases such as coronary heart disease and some cancers (Bravo, 1998; Kawabata et al., 1995; Kikuzaki et al., 1998; Slavin, 2000).

$\mathrm{FA}$ is the most abundant hydroxycinnamic acid in the cell walls of cereal grains (Andreasen et al., 2000; Lempereur et al., 1997; Smith and Hartley, 1983; Zupfer et al., 1998). In monocots such as wheat, FA is esterified to the C-5 hydroxyl groups of the arabinose residues of arabinoxylan (Hartley et al., 1990); in dicots such as sugar beet, FA is esterified to the C-2 hydroxyl groups of arabinofuranose or to the C-6 hydroxyl groups of the galactopyranose residues of pectic side chains (Ralet et al., 1994). For a complete understanding of the implications of dietary FA on human and animal health, it is necessary to preferentially clarify the mechanisms by which dietary FA is released from complex food matrices.

Since MacKezie et al. (1987) first reported their observations of feruloyl and $p$-coumaroyl esterase activities resulting in the cleavage of ester cross-linkages, feruloyl

E-mail: akatsuki@graduate.chiba-u.jp esterases (FAE) (4-hydroxy-3-methoxycinnamoyl-sugar hydrolase; EC 3.1.1.73) from various sources have been purified and partly characterized (Faulds and Williamson, 1994; Koseki et al., 1994; McCrae et al., 1994; Donaghy and McKay, 1997; Donaghy et al., 2000; Topakas et al., 2003a, 2004). Several studies of the release of FA from feruloylated polymers by FAE have indicated that the participation of a much more complicated enzymic system is needed (Castanares et al., 1992; Faulds and Williamson, 1991; McDermid et al., 1990; Wang et al., 2004). However, previous studies of the interactions of FAE have been mainly focused on enzymes such as xylanase (EC 3.2.1.8) and $\beta$-xylosidases (Bartolome et al., 1995; Faulds and Williamson, 1995; MacKenzie and Bilous, 1988; Topakas et al., 2003a; Topakas et al., 2003b; Vardakou et al., 2004; Yu et al., 2002), and there is little information on xylan-debranching enzymes such as $\alpha$-L-arabinofuranosidase (EC 3.2.1.55) or on the effect of the coexistence of xylanase and arabinofuranosidase on FAE.

It has been documented that FAEs are inducible (Bonnin et al., 2002; Brézillon et al., 1995; Faulds et al., 1997; Garcia et al., 1998; Johnson et al., 1988; MacKenzie et al., 1987; MacKenzie and Bilous, 1988; Tenkanen et al., 1991; ). de Vries et al. have demonstrated that expression of the feruloyl esterase-encoding gene from eukaryotic Aspergillus niger is regulated by xylose, arabinose and FA. Kroon et al. (1997) suggested that in human fecal inoculum FAE activity could be induced by fine bran cell wall material, but the induction of FAE activity in intestinal microflora 
is largely unknown.

In a previous study, we reported the purification and characterization of a novel FAE obtained from a typical human intestinal bacterium, Lactobacillus acidophilus (Wang et al., 2004). The N-terminal amino acid sequence of this FAE is completely different from those of other FAEs, which suggests that it may possess particular properties. In this work, we investigated the production of this FAE from L. acidophilus during growth on various carbon sources and the release of FA from complex plant cell wall polymers (wheat bran) by the enzyme in the presence or absence of xylanase and arabinofuranosidase. The primary objective of this study was to obtain further information about FAE from the intestine in order to clarify the mechanism by which FA is released from foodstuffs in the intestine.

\section{Materials and Methods}

Chemicals Wheat bran was kindly supplied by Nisshin Seifun Group Inc. (Tokyo, Japan). De-starched wheat bran (DSWB) was prepared by incubating $100 \mathrm{mg}$ wheat bran with $0.1 \mathrm{mg}$ of $\alpha$-amylase in $20 \mathrm{mM}$ sodium phosphate buffer $(\mathrm{pH} 6.9)$ at $40^{\circ} \mathrm{C}$ for $48 \mathrm{~h}$. After terminating the reaction in boiling water for $10 \mathrm{~min}$, the mixture was dialyzed extensively against distilled water (DW) with agitation and then dried in a desiccator (Kato and Matsuda, 1976).

5-O-feruloyl-L-arabinofuranose (FAA) was prepared from refined corn bran (Nihon Shokuhin Kako Co., Ltd., Tokyo, Japan) using the method of Wang et al. (2004). For the xylanase assay, 1.0\% birch wood glucuronoxylan solution was prepared using birch wood glucuronoxylan (Fluka Chemical, Milwaukee, WI, USA) as described by Miller (1959). FA and other chemicals (analytical or HPLC grade) were obtained from Wako Pure Chemical Industries (Osaka, Japan) unless otherwise indicated.

Organism and growth conditions L. acidophilus (IFO 13951), which was purchased from the Institute of Fermentation, Osaka (IFO, Osaka, Japan), was cultured in a medium containing $5 \mathrm{~g}$ of polypeptone, $5 \mathrm{~g}$ of yeast extract, $1 \mathrm{~g}$ of $\mathrm{MgSO}_{4} \cdot 7 \mathrm{H}_{2} \mathrm{O}, 0.5 \mathrm{~g}$ of Tween 80 and $5 \mathrm{~g}$ of carbon sources, such as glucose, xylose, arabinose, fructooligosaccharide (FOS), oat spelt xylan (OSX) (Sigma, St. Louis, MO, USA) or DSWB, in $1 \mathrm{~L}$ of DW without aeration or agitation at $37^{\circ} \mathrm{C}$ for 4 days, as recommended by the manufacturer.

The study of induction of FAE activity by FA was carried out using the medium stated above with OSX $(0.5 \%, \mathrm{w} / \mathrm{v})$ as a carbon source, supplemented with various concentrations of FA, followed by incubation for 3 days. For studying the interactions of enzymes, L. acidophilus was cultured using the medium stated above with DSWB $(0.5 \%, \mathrm{w} / \mathrm{v})$ as a carbon source for $60 \mathrm{~h}$.

Enzyme preparations Cells were harvested from the culture medium by centrifugation at $6,500 \times \mathrm{g}$ for $15 \mathrm{~min}$ at $4^{\circ} \mathrm{C}$. After lysozyme and ultrasonication treatment according to the methods of Wang et al. (2004), the cell wall debris was removed by centrifugation $(6,000 \times \mathrm{g}, 10$ $\min , 4^{\circ} \mathrm{C}$ ) and the supernatant obtained was used as a crude extract for the enzyme induction assay.

FAE was purified from L. acidophilus grown on DSWB, as described by Wang et al. (2004) previously to study enzyme interactions. Endo- $\beta-1,4-x y l a n a s e$ from Trichoderma viride was purchased from Sigma Chemical Co. (St. Louis, MO, USA). $\alpha$-L-Arabinofuranosidase from $A$. niger was obtained from Megazyme International Ireland, Ltd. (Wicklow, Ireland).

Enzyme assay One unit of enzyme activity was defined as the amount of enzyme that released $1 \mu \mathrm{mol}$ of $\mathrm{FA}$ (for $\mathrm{FAE}$ ), $1 \mu \mathrm{mol}$ of reducing sugar (expressed as xylose, for xylanase) or $1 \mu \mathrm{mol}$ of $p$-nitrophenol (for arabinofuranosidase) per min from its respective substrate.

FAE activity FAE activity was assayed by determining the amount of free FA released from FAA or DSWB using HPLC, as described previously (Wang et al., 2004). When DSWB was used as substrate, a $1 \mathrm{ml}$ sample of assay mixture, consisting of $10 \mathrm{mg}$ DSWB, $30 \mu \mathrm{l}$ of enzyme solution, $500 \mu \mathrm{l}$ of $0.25 \mathrm{M}$ morpholineethanesulfonic acid (MES)-NaOH buffer ( $\mathrm{pH}$ 5.6) and DW, was incubated with gentle shaking at $37^{\circ} \mathrm{C}$ for $5 \mathrm{~min}$. The reaction was terminated by heating for $3 \mathrm{~min}$ in a boiling water bath. The FA content of the samples was corrected against the "blank" - the content of FA in the crude extract when the assay mixture contained enzyme solution and DW instead of substrate.

Xylanase activity Xylanase activity was estimated by measuring the reducing sugar released from $1 \%(\mathrm{w} / \mathrm{v})$ birch wood glucuronoxylan solution, according to the method of Bailey et al. (1992), with a slight modification in that the reaction temperature was set at $37^{\circ} \mathrm{C}$ and $\mathrm{pH}$ at 5.6. Xylose was used to make the standard curve.

Arabinofuranosidase activity The assays were carried out using $p$-nitrophenol- $\alpha$-L-arabinofuranoside (Sigma) as substrate. One milliliter of the assay mixture, which consisted of $100 \mu \mathrm{l}$ of substrate solution $(20 \mathrm{mM})$ and $400 \mu \mathrm{l}$ of appropriately diluted enzyme solution in $0.25 \mathrm{M}$ MES$\mathrm{NaOH}$ buffer (pH 5.6), was incubated at $37^{\circ} \mathrm{C}$ for $30 \mathrm{~min}$. The reaction was terminated by adding $1 \mathrm{ml}$ of ice-cooled $0.5 \mathrm{M} \mathrm{Na}_{2} \mathrm{CO}_{3}$ and absorbance was measured at $405 \mathrm{~nm}$ (molecular extinction coefficient of $p$-nitrophenol: $\varepsilon=18.45$ ).

Degradation of DSWB by purified FAE The degradation of DSWB by purified FAE was carried out in a $1 \mathrm{ml}$ sample of assay mixture which consisted of $10 \mathrm{mg}$ of DSWB, $50 \mu 1$ of the purified FAE (30 mU), $500 \mu 10.25 \mathrm{M}$ MES-NaOH buffer (pH 5.6) and $\mathrm{DW}$ at $37^{\circ} \mathrm{C}$ for $30 \mathrm{~min}$. The reaction was terminated by heating for $3 \mathrm{~min}$ in a boiling water bath. The released FA was extracted and determined by HPLC (Wang et al., 2004). In addition, the influence of the presence of xylanase or arabinofuranosidase on the release of $\mathrm{FA}$ was examined by adding xylanase (final concentration, $2 \mathrm{U} \mathrm{ml}^{-1}$ in all cases) and/or arabinofuranosidase $\left(5 \mathrm{U} \mathrm{ml}^{-1}\right)$ to the assay mixture.

Extraction and quantitative determination of total FA from lignocellulosic materials The alkali-extractable FA content of DSWB and OSX (10 mg in both cases) was measured by adding $1 \mathrm{M} \mathrm{NaOH}(1 \mathrm{ml})$ and incubating at $37^{\circ} \mathrm{C}$ for $24 \mathrm{~h}$ in the dark (Garcia et al., 1998). After the $\mathrm{pH}$ was adjusted to $3.0-3.5$ with $6 \mathrm{M} \mathrm{HCl}$, the solution was 


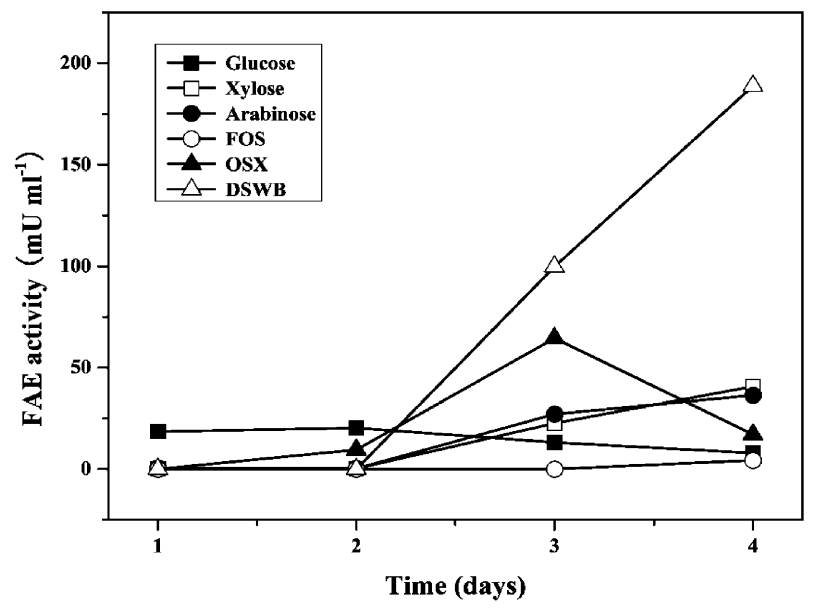

Fig. 1. Influence of various carbon sources on the production of FAE from L. acidophilus. The bacterium was grown on glucose $(\square)$, xylose $(\square)$, arabinose $(\mathbf{\bullet})$, FOS $(\bigcirc)$, $\operatorname{OSX}(\boldsymbol{\Delta})$ and $\operatorname{DSWB}(\triangle)$ over a 4-day period. FAE activity was assayed with FAA as substrate.

extracted with a double volume of ethyl acetate. The extract was then evaporated to dryness with a stream of nitrogen gas at room temperature. To the dry residues, $40 \mu 1$ of methanol/water (50:50, v/v) was added and its FA content was determined by HPLC (Wang et al., 2004).

Hydrolysis and extraction were performed in triplicate. Results are presented as the means of three replicates with standard errors where appropriate.

\section{Results and Discussion}

Effect of carbon source on the production of FAE The production of FAE from L. acidophilus grown on culture media containing different kinds of carbon sources was investigated as shown in Fig. 1. No significant differences were observed in the growth curves of bacteria cells grown on different carbon sources. FAE activities were examined with FAA as substrate in order to avoid the interference of other enzymes which would probably exist in the crude extract. Compared with a glucose carbon source, it was found that FAE activities were induced by all carbon sources except FOS. DSWB, xylose and arabinose induced FAE activity in a similar pattern: FAE activity began to increase after two days of growth. In contrast, FAE activity induced by OSX reached a maximum after three days of growth and then dropped. DSWB showed a higher inducibility than OSX. In good agreement with results obtained using FAEs from A. niger and Streptomyces avermitilis UAH30, the best production was achieved using DSWB as a carbon source (Faulds et al., 1997; Garcia et al., 1998); however, in other studies with Streptomyces spp., OSX showed greater inducibility than DSWB (Johnson et al., 1988; MacKenzie et al., 1987). Garcia et al. (1998) demonstrated that a lignocellulosic substrate was an essential requirement for induction of FAE, but in the present study FAE activity was also induced by monosaccharides.

Influence of $F A$ on the production of FAE Both DSWB

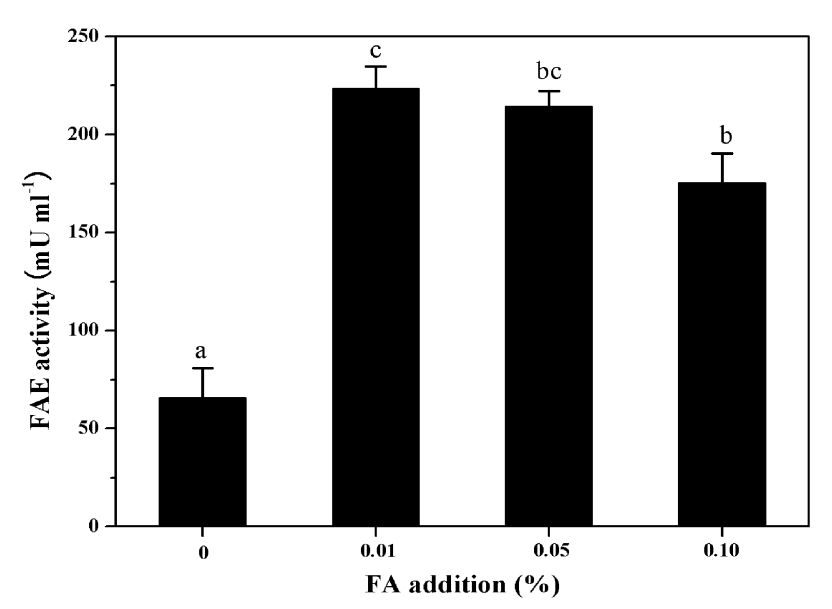

Fig. 2. Influence of FA on the production of $\mathrm{FAE}$ from $L$. acidophilus. The bacterium was grown on OSX as a carbon source with addition of $0,0.01,0.05$, and $0.1 \%(\mathrm{w} / \mathrm{v}) \mathrm{FA}$ over a 3-day period. FAE activity was assayed with FAA as substrate. The column represents the mean \pm standard deviation $(n=3)$. Analytical results for FAE activity with FA addition were assayed by Tukey's test when significant differences were obtained by one-way analysis of variance.

The STATISTICA 2000 software package (StatSoft Japan Inc., Tokyo, Japan) was used for statistical analysis. The columns with different letters differed from each other at a level of significance of $\mathrm{p}<0.05$.

and OSX induced FAE activity in L. acidophilus; DSWB induced more activity than OSX. Since there was a notable difference in FA content between DSWB and OSX, at $0.9 \%(\mathrm{w} / \mathrm{w})$ and $<0.0003 \%(\mathrm{w} / \mathrm{w})$, respectively, the effect on FAE activity of FA concentration in culture during growth was investigated. The results showed that FA concentration in culture increased during growth; however, there was no linear relationship with FAE activity (data not shown). A study of the effect of free FA on the induction of FAE activity was carried out using OSX (due to its trace amount of FA content) as a carbon source. Addition of free FA clearly stimulated FAE production, as shown in Fig. 2. Faulds et al. (1997) suggested that the production of $\mathrm{FAE}$ in $A$. niger was dependent on the amount of FA added, with the highest activity obtained in the presence of $0.03 \%(\mathrm{w} / \mathrm{v})$ of free $\mathrm{FA}$ in the tested concentration range of $0-0.03 \%$. In the present study, when the level of $\mathrm{FA}$ added was $0.01 \%$, FAE activity reached a maximum with a value of $0.22 \mathrm{U} \mathrm{ml}^{-1}$. It should be noted that the production of the FAE did not increase in direct proportion to the amount of free FA added. Another investigation with $S$. avermitilis UAH30 showed that there was no relationship between free FA concentration and FAE induction (Garcia et al., 1998), a result that is also inconsistent with this work. Our results suggest that FA is not required for F AE induction from $L$. acidophilus, but the addition of FA obviously influenced the induction of FAE activity which was not directly proportional to the FA added. It was clearly shown that FAE activity initially increased to a maximum and then declined. 


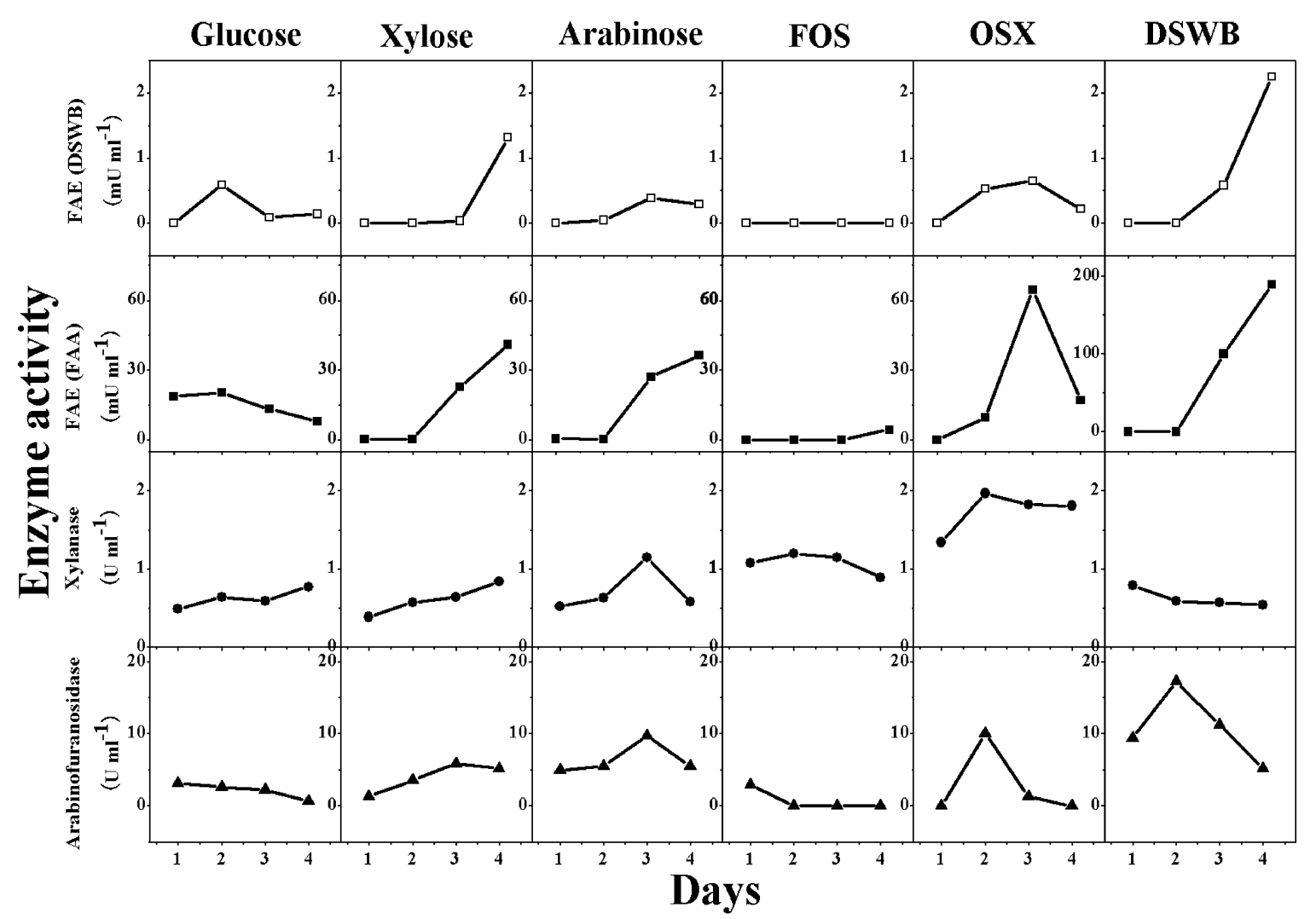

Fig. 3. Effects of various carbon sources on the activities of FAE, xylanase and $\alpha$-L-arabinofuranosidase from $L$. acidophilus. The bacterium was grown on glucose, xylose, arabinose, FOS, OSX and DSWB over a 4-day period. FAE activity was assayed with either FAA $(\square)$ or DSWB $(\square)$ as substrate. Xylanase $(\mathbf{O})$ and arabinofuranosidase $(\mathbf{\Delta})$ activities were assayed with $1 \%(\mathrm{w} / \mathrm{v})$ birch wood glucuronoxylan solution and $p$-nitrophenol- $\alpha$-L-arabinofuranoside, respectively, as described in the Materials and Methods section.

The effect of xylanase and arabinofuranosidase in crude extract on FAE activity Many studies have reported that only low levels, or no detectable levels, of free FA were released from DSWB by purified FAEs (Faulds and Williamson, 1991; Faulds and Williamson, 1995; MacKenzie and Bilous, 1988; Topakas et al., 2003a; Topakas et al., 2003 b; Topakas et al., 2004). In our previous study, purified FAE from L. acidophilus could not release FA from high molecular weight feruloylated sugar esters $\mathrm{FAX}_{N}$ (feruloylarabinoxylan) or $\mathrm{FAX}_{n}$ (feruloyl-arabinoxylan with a lesser degree of polymerization of xylopyranose than $\mathrm{FAX}_{N}$ ) (Wang et al., 2004). In this work, FA was released from DSWB by crude extracts from L. acidophilus grown on all of the carbon sources except FOS (Fig. 3). Moreover, FAE activity with DSWB as substrate was observed to be different from that using FAA as substrate when $L$. acidophilus was grown on all carbon sources. FAA can effectively block the influence of other enzymes on FAE activity as it has a specific structure for FAE, which means that FAE activity towards FAA reflects real FAE production by the microorganism. Our previous study showed that FAE activity did not change with or without the presence of xylanase when FAA was used as substrate (Wang et al., 2004). Therefore, it may be inferred that the difference between the profile of FAE activity using DSWB, a complex cell wall polymer, as substrate and the profile using FAA as substrate is due to the presence of other cell wall-degrading enzymes in the crude extract. The synergistic interaction between FAE and other enzymes, such as xylanase, has been extensively reported in the degradation of plant cell wall polysaccharides. Additionally, FA is known to be esterlinked to the arabinose sidegroups of arabinoxylans. Thus, with a high molecule substrate, the participation of FAE, xylanase and arabinofuranosidase is expected. The activities of xylanase and arabinofuranosidase in the crude extract were measured in this work. These were detected in all of the crude extracts, with maximum xylanase $\left(1.97 \mathrm{U} \mathrm{ml}^{-1}\right)$ and arabinofuranosidase activity (17.23 $\mathrm{U} \mathrm{ml}^{-1}$ ) detected when OSX and DSWB were used as carbon sources, respectively. Comparing the three enzyme activity profiles (Fig. 3) during growth on different carbon sources, it could be deduced that the bacterial regulatory mechanisms involved in the production and secretion of FAE, xylanase and arabinofuranosidase are different.

It was found in the present study that the alteration of FAE activity was closely related to xylanase and arabinofuranosidase activities during cultivation. For example, when arabinose was used as a carbon source and DSWB as substrate, the release of FA began to decline after three days of growth, in contrast to the finding that 
FAE activity increased when FAA was used as a substrate. The decrease in FAE activity with DSWB as substrate after three days of growth was consistent with the decrease in the xylanase and arabinofuransosidase activities in the same crude extract. Moreover, after one day of growth on OSX the release of FA began to elevate more rapidly with DSWB as substrate than with FAA as substrate. The significant rapid elevation of FAE activity with DSWB as substrate was completely in agreement with the observed xylanase and arabinofuranosidase activity. Further, when L. acidophilus was grown on DSWB, after two days of growth FAE activity began to increase more slowly when DSWB rather than FAA was used as substrate. This suggested that FAE activity was influenced by the decrease in xylanase and arabinofuranosidase activities. It was concluded that FAE activity was closely related to xylanase and arabinofuranosidase activities when a high molecule substrate was used. However, it should be noted that when L. acidophilus was cultivated on FOS, the lack of FAE activity detected when DSWB was used as a substrate was not due to the decrease in xylanase activity after four days of growth, because real FAE activity was very low with FAA as substrate.

It was observed that xylanase had a greater influence than arabinofuranosidase on FAE activity. In other words, in terms of their effects on FAE activity, xylanase was predominant, whereas arabinofuranosidase was subordinate. For example, when glucose was used as a carbon source, we observed after three days of growth an increase in FAE activity which was in accordance with the increase in xylanase activity, although arabinofuranosidase decreased; when xylose was used as a carbon source, the influence of xylanase and arabinofuranosidase on FAE activity was similarly observed.

Synergistic interaction between the FAE, xylanase and arabinofuranosidase In order to clarify the effect of the presence of xylanase and arabinofuranosidase on FAE activity, purified FAE and commercially available xylanase and arabinofuranosidase were used. The results are shown in Table 1. No free FA was detected using purified FAE alone when DSWB was used as substrate. Similar results have been observed for FAEs from Streptomyces olivochromogenes (Faulds and Williamson, 1991), Schizophyllum commune (MacKenzie and Bilous, 1988) and Fusarium oxysporum (Topakas et al., 2003a; Topakas et al., 2003b). FAE-III (A. niger, Faulds and Williamson, 1995) and other FAEs (Sporotrichum thermophile, Topakas et al., 2004 and Clostridium stercorarium, Donaghy et al., 2000) were able to release FA from wheat bran, suggesting that the FAE property which allows the release of FA from complex feruloylated sugar esters is dependent on the source (type) of enzyme. Our study indicated that both xylanase and arabinofuranosidase clearly stimulated the release of F A in the degradation of DSWB. On addition of xylanase or arabinofuranosidase, the amount of FA released by FAE increased from 0 to $12.4 \mathrm{nmol}$ or $3.64 \mathrm{nmol}$, respectively. The synergistic interaction between FAE and xylanase has been reported
Table 1. Synergistic interaction between FAE, xylanase and arabinofuranosidase in reconstructed mixtures.

\begin{tabular}{|c|c|}
\hline Enzyme & FA released $(\mathrm{nmol})^{\mathrm{a}}$ \\
\hline FAE & $\mathrm{ND}^{\mathrm{b}}$ \\
\hline Xylanase & ND \\
\hline Arabinofuranosidase & ND \\
\hline FAE/Xylanase & $12.4 \pm 0.52$ \\
\hline FAE/Arabinofuranosidase & $3.64 \pm 1.11$ \\
\hline Xylanase/Arabinofuranosidase & ND \\
\hline FAE/Xylanase/Arabinofuranosidase & $15.7 \pm 1.83$ \\
\hline
\end{tabular}

extensively, with the explanation that xylanase degrades the complex cell wall polysaccharides into relatively lowmolecular-weight feruloylated compounds which are more suitable for attack by FAE (Christov and Prior, 1993). However, there is little information available on the effect of arabinofuranosidase on FAE. McCrea et al. (1994) (A. awamori) and Faulds et al. (1995) (A. niger) demonstrated that the presence of arabinofuranosidase failed to increase the amount of free FA released from wheat straw xylan and maize bran, respectively. In contrast, the present study shows that arabinofuranosidase promoted FA release from DSWB by FAE, a result which is similar to two previous findings that arabinofuranosidase promoted the release of FA by FAEs $(A$. niger, de Vries et al., 2000 and A. oryzae, Tenkanen et al., 1991) from wheat flour and wheat straw arabinoxylan. It is noteworthy that the contribution of arabinofuranosidase in promoting the release of FA was only $29 \%$ of that of xylanase. When xylanase and arabinofuranosidase were present in the reaction mixture together, the released FA increased by $26 \%$ compared to the value obtained in the presence of xylanase alone. This supported the results described above (Fig. 3) which indicate that arabinofuranosidase contributed less than xylanase towards the release of FA from DSWB. Wheat arabinoxylans consist of a chain backbone of $\beta$-(1 $\rightarrow 4)$-xylopyranosyl units to which $\alpha$-L-arabinofuranosyl residues are attached through the 0-2 and/or 0-3 atoms of the xylose residues and in which FA is esterified to arabinose residues (Lzydorczyk and Biliaderis, 1992). Thus, it is possible to presume that the hydrolysis of the complex cell wall xylan backbone, which is a crucial factor in the release of FA, limits the overall reaction. Faulds et al. (1995) pointed out that high FAE activity was shown for XAF (O- $\beta$-D-xylo- 
pyranose-( $1 \rightarrow 4)-O-\beta$-D-xylopyranosyl-( $1 \rightarrow 2)$-(5-O-feruloyl)$\alpha$-L-arabinofuranosyl) and FAXX (O-(5)-O-feruloyl- $\alpha$-Larabinofuranosyl)-( $(1 \rightarrow 3)$ - $O$ - $\beta$-D-xylopyranosyl- $(1 \rightarrow 4)$-Dxylopyranose), indicating that such feruloylated fragments produced by xylanase degradation can improve $\mathrm{FAE}$ access to the ester bond. The steric hindrance of the arabinose sidegroups becomes unimportant, decreasing the promoting effect of arabinofuranosidase on $\mathrm{FAE}$ activity.

In conclusion, we have investigated the production of FAE in a typical intestinal bacterium, L. acidophilus, and suggested that the production of the FAE is not induced only by lignocellulosic substances but also by monosaccharides such as xylose and arabinose. The addition of FA clearly stimulated the induction of FAE activity. With the addition of increasing amounts of free FA, the production of $\mathrm{FAE}$ increased, reached a peak and declined. The present study also demonstrated that the participation of other cell wall-degrading enzymes is required to release FA from complex foodstuffs such as DSWB, with xylanase being predominant and arabinofuranosidase subordinate in this process.

Acknowledgements We thank the staff of the Chiba University Radioisotope Research Center for their provision of equipment and facilities.

\section{References}

Anasoma, M., Takahashi, K., Miyabe, M., Yamamoto, K., Yoshimi, N., Mori, H. and Kawazoe, Y. (1994) Inhibitory effect of topical application of polymerized ferulic acid, a synthetic lignin, on tumor promotion in mouse skin two-stage tumorigensis. Carcinogenesis 15, 2069-2071.

Andreasen, M.F., Christensen, L.P., Meyer, A.S. and Hansen, ^. (2000) Content of phenolic acid and ferulic acid dehydrodimers in 17 rye (Secale cereale L.) varieties. J. Agric. Food Chem. 48, 2837-2842.

Bailey, M.J., Biely, P. and Poutanen, K. (1992) Interlaboratory testing of methods for assay of xylanase activity. J. Biotechnol. 23, 257-270.

Bartolome, B., Faulds, C.B., Tuohy, M., Hazlewood, G.P., Gilbert, H. J. and Williamson, G. (1995) Influence of different xylanases on the activity of ferulic acid esterase on wheat bran. Biotechnol. Appl. Biochem. 22, 65-73.

Bonnin, E., Saulnier, L., Brunel, M., Marot, C., Lesage-Meessen, L., Asther, M. and Thibault, J.-F. (2002) Release of ferulic acid from agroindustrial by-products by the cell wall-degrading enzymes produced by Aspergillus niger I-1472. Enzyme Microb. Technol. 31, 1000-1005.

Bravo, L. (1998) Polyphenols: chemistry, dietary sources, metabolism, and nutritional significance. Nutr. Rev. 56, 317-333.

Brézillon, C., Kroon, P.A., Faulds, C.B., Brett, G.M. and Williamson, G. (1995) Novel ferulic acid esterases are induced by growth of Aspergillus niger on sugar-beet pulp. Appl. Microbiol. Biotechnol. 45, 371-376.

Castanares, A., McCrae, S.I. and Wood, T.M. (1992) Purification and properties of a feruloyl/ $p$-coumaroyl esterase from the fungus Penicillium pinophilum. Enzyme Microb. Technol. 14, 875884.

Christov, L.P. and Prior, B.A. (1993) Esterases of xylan-degrading microorganisms: production, properties, and significance. Enzyme Microb. Technol. 15, 460-475.

Donaghy, J.A. and McKay, A.M. (1997) Purification and character- ization of a feruloyl esterase from the fungus Penicillium expansum. J. Appl. Microbiol. 83, 718-726.

Donaghy, J.A., Bronnenmeier, K., Soto-Kelly, P.F. and McKay, A. M. (2000) Purification and characterization of an extracellular feruloyl esterase from the thermophilic anaerobe Clostridium stercorarium. J. Appl. Microbiol. 88, 458-466.

Faulds, C.B., Kroon, P.A., Saulnier, L., Thibault, J.-F. and Williamson, G. (1995) Release of ferulic acid from maize bran and derived oligosaccharides by Aspergillus niger esterases. Carbohydr. Polym. 27, 187-190.

Faulds, C.B., de Vries, R.P., Kroon, P.A., Visser, J. and Williamson, G. (1997) Influence of ferulic acid on the production of feruloyl esterases by Aspergillus niger. FEMS Microbiol. Lett. 157, 239244.

Faulds, C.B. and Williamson, G. (1991) The purification and characterization of 4-hydroxy-3-methoxycinnamic (ferulic) acid esterase from Streptomyces olivochromogenes. J. Gen. Microbiol. 137, 2337-2345.

Faulds, C.B. and. Williamson, G. (1994) Purification and characterization of a ferulic acid esterase FAE-III from Aspergillus niger: specificity for the phenolic moiety and binding to microcrystalline cellulose. Microbiology 140, 779-787.

Faulds, C.B. and Williamson, G. (1995) Release of ferulic acid from wheat bran by a ferulic acid esterase (FAE-III) from Aspergillus niger. Appl. Microbiol. Biotechnol. 43, 1082-1087.

Garcia, B.L., Ball, A.S., Rodriguez, J., Pérez-Leblic, M.I., Arias, M.E. and Copa-Patiño, J.L. (1998) Induction of ferulic acid esterase and xylanase activities in Streptomyces avermitilis UAH30. FEMS Microbiol. Lett. 158, 95-99.

Hartley, R.D., Morrison III, W.H., Himmelsbach, D.S. and Borneman, W.S. (1990) Cross-linking of cell wall phenolic arabinoxylans in graminaceous plants. Phytochemistry 29, 3705-3709.

Huang, M.T., Smart, R.C., Wong, C.Q. and Conney, A.H. (1988) Inhibitory effect of curcumin, chlorogenic acid, caffeic acid, and ferulic acid on tumor promotion in mouse skin by 12 O-tetradecanoylphorbol-13-acetate. Cancer Res. 48, 5941-5946.

Johnson, K.G., Harrison, B.A., Schneider, H., MacKenzie, C.R. and Fontana, J.D. (1988) Xylan-hydrolyzing enzymes from Streptomyces spp. Enzyme Microb. Technol. 10, 403-409.

Kato, Y. and Matsuda, K. (1976) Presence of a xyloglucan in the cell wall of phaseolus aureus hypocotyls. Plant cell physiol. 17, $1185-1198$.

Kawabata, K., Yamamoto, T., Hara, A., Shimizu, M., Yamada, Y., Matsunaga, K., Tanaka, T. and Mori, H. (1995) Modifying effects of ferulic acid on azoxymethane-induced colon carcinogenesis in F344 rats. Cancer Lett. 157, 15-21.

Kikuzaki, H., Hisamoto, M., Hirose, K., Akiyama, K. and Taniguchi, H. (2002) Antioxidant properties of ferulic acid and its related compounds. J. Agric. Food Chem. 50, 2161-2168.

Koseki, T., Furuse, S., Iwano, K. and Matsuzawa, H. (1998) Purification and characterization of a feruloyl esterase from Aspergillus awamori. Biosci. Biotechnol. Biochem. 62, 2032-2034.

Kroon, P.A., Faulds, C.B., Ryden, P., Robertson, J.A. and Williamson, G. (1997) Release of covalently bound ferulic acid from fiber in the human colon. J. Agric. Food Chem. 45, 661-667.

Lempereur, I., Rouau, X. and Abecassis, J. (1997) Genetic and agronomic variation in arabinoxylan and ferulic acid contents of durum wheat (Triticum durum L.) grain and its milling fractions. J. Cereal. Sci. 25, 103-110.

Lzydorczyk, M.S. and Biliaderis, C.G. (1992) Influence of structure on the physicochemical properties of wheat arabinoxylan. Carbohydr. Polym. 17, 237-247.

MacKenzie, C.R. and Bilous, D. (1988) Ferulic acid esterase activity from Schizophyllum commune. Appl. Environ. Microbiol. 54, 1170-1173.

MacKenzie, C.R., Bilous, D., Schneider, H. and Johnston, K.G. (1987) Induction of cellulolytic and xylanolytic enzyme sys- 
tems in Streptomyces spp. Appl. Environ. Microbiol. 53, 28352839.

McCrea, S.I., Leith, K.M., Gordon, A.H. and Wood, T.M. (1994) Xylan-degrading enzyme system produced by the fungus Aspergillus awamori: isolation and characterization of a feruloyl esterase and a p-coumaroyl esterase. Enzyme Microb. Technol. $16,826-834$.

McDermid, K.P., MacKenzie, C.R. and Forsberg, C.W. (1990) Esterase activities of Fibrobacter succinogenes subsp. Succinogenes S85. Appl. Environ. Microbiol. 56, 127-132.

Meyer, A.S., Donovan, J.L., Pearson, D.A., Waterhouse, A.L. and Frankel, E.N. (1998) Fruit hydroxycinnamic acids inhibit human low-density lipoprotein oxidation in vitro. J. Agric. Food Chem. 46, 1783-1787.

Miller, G.L. (1959) Use of dinitrosalicylic acid reagent for determination of reducing sugars. Anal. Chem. 31, 426-428.

Nicolosi, R.J., Ausman, L.M. and Hegsted. D.M. (1991) Rice bran oil lowers serum total and low density lipoprotein cholesterol and apo B levels in nonhuman primates. Atherosclerosis $\mathbf{8 8 , 1 3 3 -}$ 142.

Ohta, T., Semboku, N., Kuchii, A., Egashira, Y. and Sanada, H. (1997) Antioxidant activity of corn bran cell-wall fragments in the LDL oxidation system. J. Agric. Food Chem. 45, 1644-1648.

Ralet, M.-C., Faulds, C.B., Williamson, G. and Thibault, J.-F. (1994) Degradation of feruloylated oligosaccharides from sugar-beet pulp and wheat bran by ferulic acid esterases from Aspergillus niger. Carbohydr. Res. 263, 257-269.

Slavin, J.L. (2000) Whole grains, refined grains and fortified refined grains: what's the difference? Asia Pac. J. Clin. Nutr. 9, s23-s27.

Smith, M.M. and Hartley, R.D. (1983) Occurrence and nature of ferulic acid substitution of cell-wall polysaccharides in graminaceous plants. Carbohydr. Res. 118, 65-80.

Tenkanen, M., Schuseil, J., Puls, J. and Poutanen, K. (1991) Production, purification and characterization of an esterase liberating phenolic acids from lignocellulosics. J. Biotechnol. 18, 69-84.
Topakas, E., Stamatis, H., Biely, P., Kekos, D., Macris, B.J. and Christakopoulos, P. (2003a) Purification and characterization of a feruloyl esterase from Fusarium oxysporum catalyzing esterification of phenolic acids in ternary water-organic solvent mixtures. J. Biotechnol. 102, 33-44.

Topakas, E., Stamatis, H., Mastihubova, M., Biely, P., Kekos, D., Macris, B.J. and Christakopoulos, P. (2003b) Purification and characterization of a Fusarium oxysporum feruloyl esterase (FoFAE-I) catalyzing transesterification of phenolic acid esters. Enzyme Microb. Technol. 33, 729-737.

Topakas, E., Stamatis, H., Biely, P. and Christakopoulos, P. (2004) Purification and characterization of a type B feruloyl esterase (StFAE-A) from the thermophilic fungus Sporotrichum thermophile. Appl. Microbiol. Biotechnol. 63, 686-690.

Vardakou, M., Katapodis, P., Topakas, E., Kekos, D., Macris, B.J. and Christakopoulos, P. (2004) Synergy between enzymes involved in the degradation of insoluble wheat flour arabinoxylan. Innovative food science and emerging technologies. $\mathbf{5}$, 107-112.

de Vries, R.P., Kester, H.C.M., Poulsen, C.H., Benen, J.A.E. and Visser, J. (2000) Synergy between enzymes from Aspergillus involved in the degradation of plant cell wall polysaccharides. Carbohydr. Res. 327, 401-410.

Wang, X.K., Geng, X., Egashira, Y. and Sanada, H. (2004) Purification and characterization of a feruloyl esterase from the intestinal bacterium Lactobacillus acidophilus. Appl. Environ. Microbiol. 70, 2367-2372.

Yu, P., Maenz, D.D., McKinnon, J.J., Racz, V.J. and Christensen, D. A. (2002) Release of ferulic acid from oat hulls by Aspergillus ferulic acid esterase and Trichoderma xylanase. J. Agric. Food Chem. 50, 1625-1630.

Zupfer, J.M., Churchill, K.E., Rasmusson, D.C. and Fulcher, R.G. (1998) Variation in ferulic acid concentration among diverse barley cultivars measured by HPLC and microspectrophotometry. J. Agric. Food Chem. 46, 1350-1354. 